\title{
Dependence of phosphorus gettering and hydrogen passivation efficacy on grain boundary type in multicrystalline silicon
}

\author{
P. Karzel, ${ }^{1}{ }^{1, a)}$ M. Ackermann, ${ }^{1}$ L. Gröner, ${ }^{1}$ C. Reimann, ${ }^{2}$ M. Zschorsch, ${ }^{3}$ S. Meyer, ${ }^{4}$ \\ F. Kiessling, ${ }^{5}$ S. Riepe, ${ }^{6}$ and G. Hahn ${ }^{1}$ \\ ${ }^{1}$ Department of Physics, University of Konstanz, 78464 Konstanz, Germany \\ ${ }^{2}$ Fraunhofer IISB, Schottkystr. 10, 91058 Erlangen, Germany \\ ${ }^{3}$ Fraunhofer THM, Am-St. Niclas-Schacht 13, 09599 Freiberg, Germany \\ ${ }^{4}$ Fraunhofer CSP, Walter-Hülse-Str. 1, 06120 Halle, Germany \\ ${ }^{5}$ Leibniz IKZ, Max-Born-Str. 2, 12489 Berlin, Germany \\ ${ }^{6}$ Fraunhofer ISE, Heidenhofstr. 2, 79110 Freiburg, Germany
}

(Received 17 September 2013; accepted 6 December 2013; published online 27 December 2013)

This investigation analyzes the dependency of minority charge carrier lifetime values at grain boundaries in multicrystalline silicon on the grain boundary type after $\mathrm{P}$ gettering and/or firing of $\mathrm{SiN}_{\mathrm{x}}: \mathrm{H}$ layers deposited by plasma enhanced chemical vapor deposition. To get a broad statistics, a new method to determine the coincidence site lattice grain boundary types on large scale throughout entire $50 \times 50 \mathrm{~mm}^{2}$ samples is combined with spatially resolved lifetime-calibrated photoluminescence measurements and mappings of the interstitial iron concentration. As an evaluation of the lifetime data at grain boundaries in comparison to the recombination activity of the bordering grains, lifetime contrast values are calculated. The correlation of this dependency on the grain boundary type with the impurity concentration is analyzed by the investigation of multicrystalline samples from two different ingots grown by directional solidification with different crucible material qualities. A dependency of the efficacy of all applied processes on the grain boundary type is shown based on broad statistics - higher coincidence site lattice indexes correlate with a decrease of median lifetime values after all processes. Hydrogenation of both grains and grain boundaries is found to be more effective in cleaner samples. Extended getter sinks, as a P emitter, are also beneficial to the efficacy of hydrogenation. The lifetime contrast values are dependent on the degree of contamination of the multicrystalline silicon material. In cleaner samples, they rather decrease after the processes; in standard solar-grade material, they increase after $\mathrm{POCl}_{3}$ diffusion and decrease again after subsequent hydrogenation. No correlation with the interstitial iron concentration is found. (C) 2013 AIP Publishing LLC. [http://dx.doi.org/10.1063/1.4856215]

\section{INTRODUCTION}

Directionally solidified multicrystalline silicon (mc-Si) wafers offer a good compromise between production costs and solar cell efficiency. However, compared to monocrystalline silicon wafers, mc-Si wafer quality is lowered by higher impurity concentration, ${ }^{1,2}$ grain boundaries, ${ }^{3}$ and dislocations. ${ }^{4}$ This results in lower minority charge carrier lifetimes in as-grown wafers. Average lifetime values can be significantly enhanced during standard solar cell production processes, such as $\mathrm{POCl}_{3}$ diffusion for emitter formation ${ }^{5-9}$ and hydrogenation of the wafer bulk during firing of hydrogen-rich $\mathrm{SiN}_{\mathrm{x}}: \mathrm{H}$ layers deposited by plasma enhanced chemical vapor deposition (PECVD) ${ }^{5-8}$

The effect of $\mathrm{P}$ gettering on the average minority charge carrier lifetime is well known and understood. ${ }^{10-14}$ Hydrogenation is just as well known to significantly improve the average bulk minority charge carrier lifetime of $\mathrm{mc}-\mathrm{Si}$ wafers. ${ }^{6,8,15-18}$ This improvement is explained by the passivation of defects by atomic $\mathrm{H}$. There are on-going discussions not only about the exact mechanism but also about which defects and impurities can be passivated. ${ }^{16,18,19}$

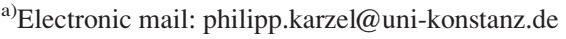

However, the local effect of the two processes to grain boundaries can be contrary in material with high impurity concentration. Because grain boundaries are heavily decorated by transition metal precipitates that dissolve during high temperature treatments, such as $\mathrm{POCl}_{3}$ diffusion, and contaminate grain boundaries with dissolved metal impurities, ${ }^{20,21}$ the lifetime locally decreases at grain boundaries during $\mathrm{P}$ gettering. ${ }^{22}$ Additionally, grain boundaries are getter sinks for metal impurities that diffuse through the crystal during $\mathrm{POCl}_{3}$ diffusion. After such a possible decrease of lifetime due to $\mathrm{POCl}_{3}$ diffusion, it can be re-increased by subsequent hydrogenation. The net change in minority charge carrier lifetime after the two processes still leads to higher lifetimes at some grain boundaries but the improvement is rather moderate ${ }^{22}$ and varies. ${ }^{23}$ The beneficial effect of hydrogenation to material quality is usually more prominent at grain boundaries than in grains. ${ }^{24}$

Former investigations indicate a possible correlation between the coincidence site lattice (CSL) grain boundary type $^{25}$ and the efficacy of $\mathrm{P}$ gettering ${ }^{26}$ or a passivation of the recombination activity by $\mathrm{H}$ at different CSL grain boundaries. $^{23,27-32}$ The statistics in all of these analyses could only be derived from measurements at a small selection of points, because the CSL grain boundary types were 
detected with electron backscatter diffraction (EBSD) $)^{33}$ and only a small part of the sample area could be analyzed with this microscopic analysis method.

The present analysis uses a new tool to analyze the types of nearly all grain boundaries throughout a whole wafer. ${ }^{34}$ This tool allows the detection of the orientation matrix of nearly each grain on a large wafer area (maximum of $156 \times 156 \mathrm{~mm}^{2}$ ) with short measuring times. It is based on selected X-ray Laue scans (Laue X-ray diffraction, Laue $\mathrm{XRD)}$ ). Only one scan per grain is performed positioned at the most distant inner point from all surrounding grain boundaries. These points are detected by the computer-supported analysis of 16 pictures, each taken with illumination by light emitting diodes (LEDs) from different angles. Only grains exceeding the size of the $500 \mu \mathrm{m}$ measuring diameter of the $\mathrm{X}$-ray spot are analyzed. From the comparison of the grain orientation of neighboring grains, the grain boundary types can be determined. This method is used to enlarge the statistics behind the investigations compared to existing literature. The combination of this information with the spatially resolved lifetime-calibrated photoluminescence $(\mathrm{PL})^{35-37}$ images evaluated at grain boundaries of $\mathrm{mc}-\mathrm{Si}$ wafers-ascut, after $\mathrm{POCl}_{3}$ diffusion and after $\mathrm{POCl}_{3}$ and subsequent hydrogenation during firing of $\mathrm{PECVD}-\mathrm{SiN}_{\mathrm{x}}: \mathrm{H}$ layers (on a neighboring sample with similar grain structure and impurity distribution)—generates a reliable and large statistics of the dependence of lifetime values after the different processing steps on the grain boundary type. Additionally, this dependence is analyzed on further neighboring samples that were hydrogenated without former $\mathrm{P}$ gettering. The pixel size of PL images in this investigation is $50 \mu \mathrm{m}$. In the following, at a grain boundary is referred to as the area covered by pixels of a PL image that are crossed by a grain boundary.

As the lifetime at a grain boundary $\tau_{G B}$ has to be compared to the lifetime $\tau_{0}$ in the neighboring grains, the lifetime contrast $C_{\tau}$ was calculated. A description of this quantity is given in Sec. II.

To get information about a possible correlation of the dependence of lifetime changes on the grain boundary type with the interstitial Fe distribution, the interstitial Fe concentration $\left[\mathrm{Fe}_{\mathrm{i}}\right]$ was measured spatially resolved (based on lifetime-calibrated PL images) ${ }^{38,39}$ for all samples after all processing steps.

\section{LIFETIME CONTRAST VALUE}

Commonly, the difference between PL intensities at a grain boundary and the intensity in the neighboring grains normalized to the intensity in the grains is called PL contrast value (compare Refs. 28 and 32). Since in this investigation, the PL images are lifetime-calibrated, a lifetime contrast value $C_{\tau}$ is defined analogically

$$
C_{\tau}=\frac{\tau_{0}-\tau_{G B}}{\tau_{0}} .
$$

$\tau_{G B}$ represents a lifetime value at a grain boundary (in this investigation 1 pixel equals $50 \mu \mathrm{m}$ ) and $\tau_{0}$ the value of two identical intra-grain lifetime values $\tau_{0, \text { left }}$ and $\tau_{0, \text { right }}$ positioned on opposite sides of a line scan in the lifetime- calibrated PL image crossing the analyzed point on the grain boundary. The line scans are not symmetrical for all points along the grain boundaries: for many the lifetime values $\tau_{0, \text { left }}$ and $\tau_{0, \text { right }}$ in the two neighboring grains differ.

The two intra-grain lifetime values were determined by searching the points left and right of the grain boundary where the slopes of a lifetime line scan crossing the analyzed point at the grain boundary are zero. The lifetime values at these points were defined to be $\tau_{0, \text { left }}$ and $\tau_{0, \text { right }}$.

The average value $\tau_{\text {average }}$ of $\tau_{0, \text { left }}$ and $\tau_{0, \text { right }}$ was accepted as $\tau_{0}$ if the following expression was smaller than $20 \%$ :

$$
\Delta \tau_{\text {norm }}=\left|\frac{\tau_{0, \text { left }}-\tau_{0, \text { right }}}{\tau_{\text {average }}}\right| .
$$

To get more points fulfilling this condition and to manage the situation at very bended grain boundaries, 21 line scans were performed at one single point at a grain boundary: perpendicular to the grain boundary and in an angle corridor of $\pm 10^{\circ}$ to the lead in $1^{\circ}$ steps. From these line scans, only the one with the smallest $\Delta \tau_{\text {norm }}$ was picked. If $\Delta \tau_{\text {norm }}$ for this line scan was smaller than $20 \%$, the point was taken into the statistics.

As contrast values from two or even three PL images after different processing steps shall be compared, the above described requirements were requested to be fulfilled by all PL images together at the same position on a grain boundary.

Note that the lifetime contrast is dependent on the generation rate. ${ }^{32}$ Because of this dependence, it is very important to know the generation rate. In this investigation, all PL measurements were taken with a photon generation flux of $g=1.75 \times 10^{-17} \mathrm{~s}^{-1} \mathrm{~cm}^{-2}$. This generation rate is slightly higher than the generation rate of 1 sun.

\section{EXPERIMENT}

Lattice defects, such as metal impurities, dislocation bundles, grain boundaries, inclusions, and precipitates are responsible for lifetime-limiting recombination processes. The content of impurities and their distribution in a directionally solidified silicon ingot is already determined by the starting conditions. Challenges start with a proper choice of the growth facilities, where impurities are one issue to consider. Since the crucibles themselves are a source of impurities, we investigated the influence of a standard and a high-purity crucible on the ingot properties keeping the coating purity high and unchanged.

Beside the different crucible purity, the two applied crucibles also significantly differ in wall thickness, resulting in different heat transfer properties during melting and solidification phase of the feedstock. As a consequence, the melting time in the standard crucible with thicker walls of $25 \mathrm{~mm}$ is longer compared to the high-purity crucible built of fused silica plates of $5 \mathrm{~mm}$ thickness. The melt is about 1 to $1.5 \mathrm{~h}$ longer in contact with the coated standard crucible than with the equally coated high-purity crucible and hence might dissolve a higher amount of impurities. Differences in the 
impurity concentrations of the melt result then in different impurity concentrations in the as-grown ingots. In order to obtain very similar axial impurity distributions in both ingots, the solid-liquid interfaces were kept flat or slightly curved during the solidification processes. The two Gen1sized mc-Si ingots have been grown by the vertical gradient freeze method with a growth velocity of around $1 \mathrm{~cm} / \mathrm{h}$. The carbon and oxygen concentrations have been adjusted by gas managements. The grain diameters of the resulting wafers were ingot-height-dependent comparable for the two grown ingots.

The expression solar-grade refers here and in the following not to the feedstock - that was of electronic-grade quality - but to the conditions of crystallization. The ingots of Gen1 size were produced within the German research cluster "SolarWinS" and in the following are referred to as:

- Ingot 1: solidified in a standard solar-grade crucible,

- Ingot 2: solidified in a high purity fused silica crucible.

A detailed description of production and properties of ingot 1 and an ingot similar to ingot 2 can be found in Ref. 40.

The investigated wafers have been selected carefully out of the ingots at similar mid-ingot height position in order to exclude segregation-dependent effects. Three vertically directly neighboring mc-Si wafers (B doped, resistivity $1.5 \Omega \mathrm{cm}$, size $156 \times 156 \mathrm{~mm}^{2}$, and thickness $200 \mu \mathrm{m}$ ) out of each ingot with very similar grain structure and very similar lifetime distribution were cut into samples of $50 \times 50 \mathrm{~mm}^{2}$. The three neighboring samples of one ingot were arranged in three groups according to the different processing steps that were supposed to be applied to them

- Group A: P gettering only, with subsequent emitter removal,

- Group B: P gettering with subsequent deposition (twosided) and firing of PECVD $\mathrm{SiN}_{\mathrm{x}}: \mathrm{H}$ layers and terminal removal of those layers and the emitter,

- Group C: deposition (two-sided), firing and removal of PECVD SiN $\mathrm{N}_{\mathrm{x}}: \mathrm{H}$ layers only.

A process flow of the experiment can be seen in Fig. 1. At first, the character of most of the grain boundaries of the samples was analyzed. If a grain exceeded the size of the $500 \mu \mathrm{m}$ measuring diameter of the X-ray spot, one point per grain was chosen to be analyzed. These points were detected by an optical grain structure analysis of the samples, and an $\mathrm{X}$-ray based analysis determined the grain orientation by Bragg reflection at these positions. ${ }^{34}$ From the difference in orientation of directly neighboring grains, the CSL types of the grain boundaries were determined throughout the whole sample area.

All samples received a chemical polishing etch removing $20 \mu \mathrm{m}$ (including the damage from wire sawing) from each surface. Afterwards, the samples were treated with $\mathrm{HCl}$ and $\operatorname{HF}(2 \%)$.

A piranha cleaning ${ }^{41}$ combined with a $\operatorname{HF}(5 \%)$ dip prepared all samples for surface passivation using quinhydronemethanol. ${ }^{42-44}$ The minority charge carrier lifetime of all samples was measured by the quasi-steady state photoconductance method (QSSPC) ${ }^{45}$ and PL images ${ }^{35}$ with a resolution of

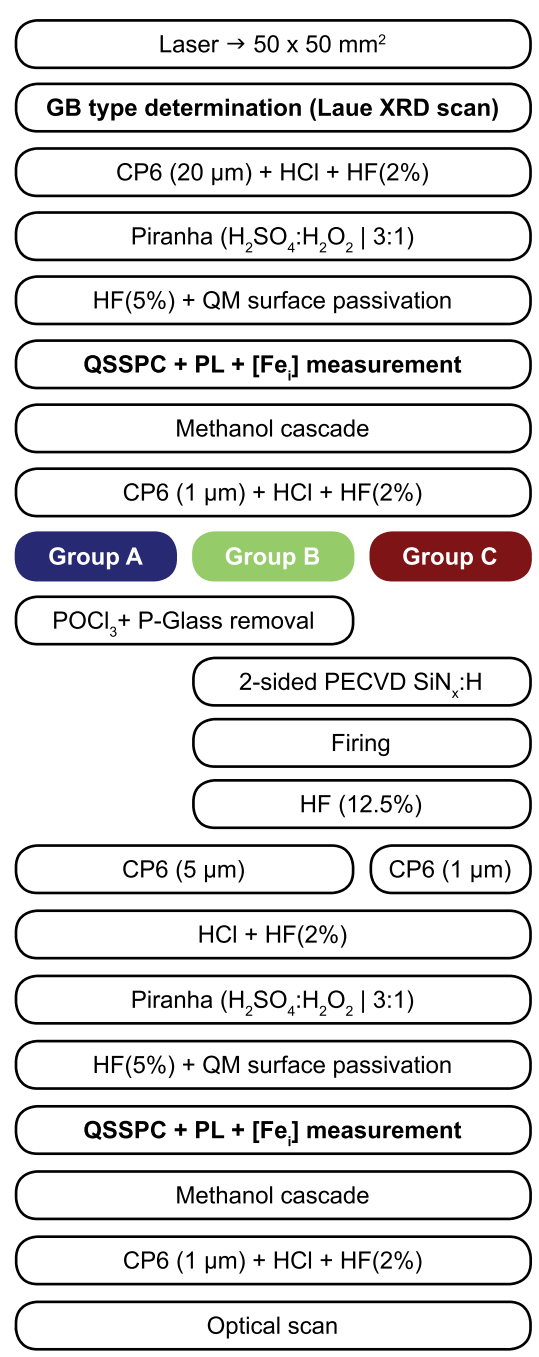

FIG. 1. Processing of mc-Si samples (B doped, $1.5 \Omega \mathrm{cm}$, as-cut thickness $200 \mu \mathrm{m})$.

$50 \mu \mathrm{m}$ were taken. The error of lifetime values detected by QSSPC measurements is specified to be less than $1 \%$ for lifetime values below $60 \mu \mathrm{s}$. The error increases to $10 \%$ for $230 \mu$ s minority charge carrier effective lifetimes. ${ }^{45}$

The PL images were calibrated to values of the excess charge carrier density $\Delta n$ by the results of the QSSPC measurements. As the sensitivity of the coil of the QSSPC setup used to measure the conductance of the samples spatially varies, an area-weighted sensitivity function ${ }^{46}$ was applied to calibrate the PL images. The lifetime-calibration was performed based on the relationship between effective lifetime $\tau_{e f f}$ and generation rate $G$ for steady state ${ }^{36}$

$$
\tau_{e f f}=\frac{\Delta n}{G} .
$$

A second lifetime measurement with QSSPC and PL was performed after illuminating the samples until all $\mathrm{FeB}$ pairs were dissociated as described in Ref. 19.

The quinhydrone-methanol residues at the sample surfaces were removed by a methanol cascade ${ }^{19,47}$ and a chemical polishing etch $(1 \mu \mathrm{m})$ with subsequent $\mathrm{HCl}$ and $\mathrm{HF}(2 \%)$ treatment. 
Samples from group A and group B underwent a $\mathrm{POCl}_{3}$ diffusion $\left(50 \Omega / \square\right.$, processed at $\left.840^{\circ} \mathrm{C}\right)$ and a phosphorus silicate glass etch in diluted $\operatorname{HF}(2 \%)$. The emitter of samples from group A was removed during a chemical polishing etch removing $5 \mu \mathrm{m}$ from each surface. The samples were treated with $\mathrm{HCl}$ and $\mathrm{HF}(2 \%)$.

$75 \mathrm{~nm}$ thick $\mathrm{SiN}_{\mathrm{x}}: \mathrm{H}$ layers were deposited on both sides of samples from group B and group C by PECVD in a direct plasma low frequency reactor from Centrotherm at $400^{\circ} \mathrm{C}$. These samples were fired in a conventional belt furnace at peak temperatures higher than $700^{\circ} \mathrm{C}$ to in-diffuse $\mathrm{H}$ into the bulk of the samples from the hydrogen-rich $\mathrm{SiN}_{\mathrm{x}}$ layers. Afterwards the $\operatorname{SiN}_{\mathrm{x}}: \mathrm{H}$ layers were etched off in $\operatorname{HF}(12.5 \%)$ and the sample surfaces (group B only) were treated with a chemical polishing removing $5 \mu \mathrm{m}$ from both surfaces, in order to take off the emitter. From the surfaces of samples from group $\mathrm{C}, 1 \mu \mathrm{m}$ was removed by chemical polishing to assure same surface conditions for all samples.

All samples were prepared for lifetime measurements as described above. Again lifetime and $\left[\mathrm{Fe}_{\mathrm{i}}\right]$ were determined by QSSPC and PL imaging. After cleaning the samples, images of all samples were taken by optical scans.

Note that this investigation does not evaluate the change in recombination activity of the grain boundaries quantitatively-for reasons explained in more detail in Sec. V-but reflects the situations at the grain boundaries close to reality, where a solar cell is illuminated homogeneously by the sun.

All lifetime-calibrated PL images of neighboring samples were computer-supported spatially correlated in that way that same positions matched each other in the different images. Note that small deviations of the grain boundary positions are possible because a part of the investigation (group $\mathrm{A} / \mathrm{B}$ ) was carried out on neighboring samples. This could have been avoided by etching off the emitter of samples from group A and taking lifetime-calibrated PL images, before subsequently hydrogenating the samples by firing PECVD $\mathrm{SiN}_{\mathrm{x}}: \mathrm{H}$ layers, instead of processing the neighboring samples from group B. But, as a pre-experiment revealed, this procedure is less effective in improving the lifetime, especially at grain boundaries, and does not display the processing of solar cells in the same way. Fig. 2 shows - besides the results of the described experiment - the comparison of lifetime-calibrated PL images of two neighboring samples after firing PECVD $\mathrm{SiN}_{\mathrm{x}}: \mathrm{H}$ layers with (top right) and without (bottom right) an emitter present during firing. A clear superiority both in the average lifetimes and in the local lifetimes at grain boundaries of the sample fired with emitter is visible. The solubility of many transition metal impurities is higher in $\mathrm{P}$ doped $\mathrm{Si}$ than in $\mathrm{B}$ doped $\mathrm{Si}^{48}$ and the observed superiority therefore is very probable explained by a further gettering process during firing, where impurities (e. g. released from metal precipitates) were driven into the emitter that was removed afterwards before the final lifetime measurement. For this reason, in this investigation, neighboring samples were analyzed.

Finally, as described in Sec. II, the contrast values were calculated for data points on the grain boundaries fulfilling the requested conditions and $\left[\mathrm{Fe}_{\mathrm{i}}\right]$ maps were calculated from the two lifetime-calibrated PL images before and after dissociating $\mathrm{FeB}$ pairs by illumination.

\section{RESULTS}

Fig. 2 shows spatially exactly correlated lifetimecalibrated PL images of a mc-Si sample from ingot 2 as-grown (top left, only a saw damage etch was carried out before the measurement), after $\mathrm{P}$ gettering and both-sided emitter removal (bottom left) and a neighboring sample with very similar grain structure and very similar as-grown lifetime distribution after $\mathrm{P}$ gettering and hydrogenation (top right). These samples were processed as described in Sec. III. The arithmetic averages of the lifetime values of these three lifetime maps are given on top or bottom of the images. A comparison between the images after $\mathrm{POCl}_{3}$ diffusion and after $\mathrm{POCl}_{3}$ diffusion with subsequent firing of PECVD $\mathrm{SiN}_{\mathrm{x}}: \mathrm{H}$ layers shows that the recombination activity at some grain boundaries is strongly reduced after firing; while at others, it is still high compared to bordering grains. This observation serves as further motivation for grain boundary type resolved investigations of the changes in lifetime. In order to have a possibility to distinguish between increased recombination activities in the PL images that originate from grain boundaries and those that originate from dislocations, the left part of Fig. 3 shows an optical scan of the sample analyzed in Fig. 2.

The right hand side of Fig. 3 connects the as-grown lifetimes of Fig. 2 (top left) to the different grain boundary types
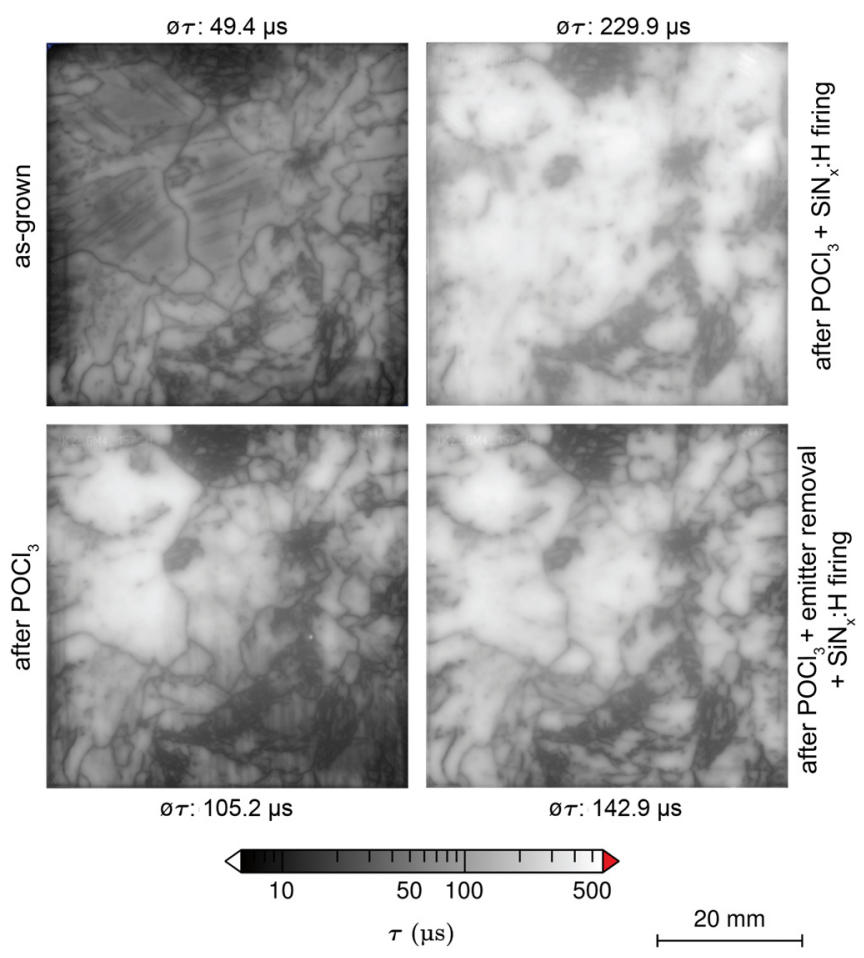

FIG. 2. Spatially exactly correlated lifetime-calibrated PL images of mc-Si samples from ingot 2 (surface passivation by quinhydrone-methanol). The left images and the right bottom image show the same sample after different processing steps: as-grown (top left); after $\mathrm{P}$ gettering and etching off the emitters (bottom left); after P gettering, etching off the emitters, firing and etching off two-sided PECVD $\mathrm{SiN}_{\mathrm{x}}: \mathrm{H}$ layers (bottom right). The top right image shows a directly neighboring sample with very similar grain structure and very similar as-grown lifetime distribution after $\mathrm{P}$ gettering, firing (without removing the emitter before depositing the $\mathrm{SiN}_{\mathrm{x}}: \mathrm{H}$ layers), and etching off two-sided PECVD $\mathrm{SiN}_{\mathrm{x}}: \mathrm{H}$ layers and the emitters. The average lifetime values after the different processing steps are shown on top or bottom of the images. 


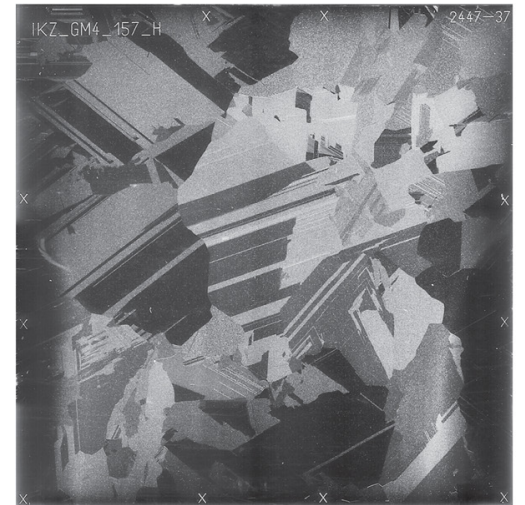

(a)

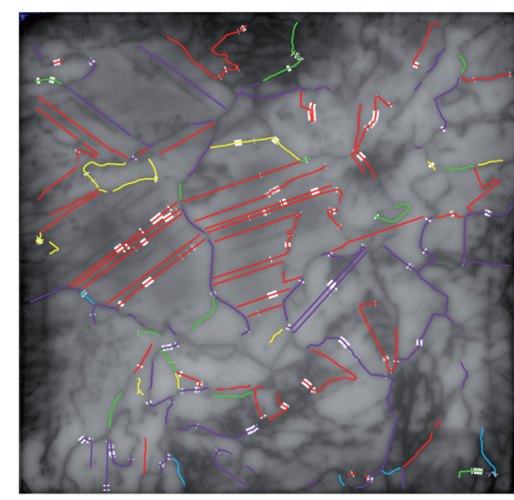

(b)

$20 \mathrm{~mm}$

FIG. 3. (a) Optical scan of bottom/top left sample from Fig. 2. (b) Lifetime map from top left image of Fig. 2 where the grain boundary types are marked with colors: red $-\Sigma 3$, yellow $-\Sigma 9$, green $-\Sigma 27$, blue-other $\Sigma$, purple-RA. The points on the colored lines, where the conditions of Sec. II are fulfilled and lifetime contrasts could be calculated, are additionally marked with a white frame. The types of grain boundaries that are not marked at all could not be detected.

that were determined from Laue XRD. The colored line grid with the grain boundary types was exactly correlated with the PL images. At some grain boundaries, the grain boundary character could not be determined correctly, because the grain size of the bordering grains was smaller than the $500 \mu \mathrm{m}$ measuring diameter of the X-ray spot or because the optical determination of the grain positions did not work out and the grain boundary type calculation was performed with orientations of grains without a common grain boundary. Those grain boundaries are not marked and are not taken into account for the analysis. The different types are indicated by different colors. The points on the colored lines, where the conditions of Sec. II are fulfilled and lifetime contrasts could be calculated, are additionally marked with a white frame. Those points exhibit very similar lifetime values in the two bordering grains on lines crossing the grain boundary at the positions marked in white. The grain boundary types referred to as "other $\Sigma$ " are CSL grain boundaries that occur with less frequency. Grain boundaries where the lattice atoms of neighboring grains do not show a regular coincidence are called random angle (RA) grain boundaries and cannot be classified as CSL grain boundaries.

At the positions of the colored marks (including the white framed regions) at the grain boundaries, the lifetime values in three of the lifetime-calibrated PL images of Fig. 2 (as-grown, after $\mathrm{POCl}_{3}$, after $\mathrm{POCl}_{3}+\mathrm{SiN}_{\mathrm{x}}: \mathrm{H}$ firing) were analyzed to learn more about the influence of the different processing steps on the recombination activities at different grain boundary types. Up to 6000 points form the statistics for one grain boundary type. Note that the three PL images are spatially exactly correlated and that the observation of the evolution of one single data point during the different processes is possible. The described analysis was analogically carried out for a directly neighboring sample with a grain structure very similar to the ones presented in Fig. 2 that was fired after depositing PECVD $\mathrm{SiN}_{\mathrm{x}}: \mathrm{H}$ layers without previous $\mathrm{POCl}_{3}$ diffusion (group $\mathrm{C}$ in Fig. 1). The results are presented in the following sections.

\section{A. Lifetime values at different grain boundary types as-grown, after $\mathrm{POCl}_{3}$ diffusion and/or firing of PECVD $\mathrm{SiN}_{\mathrm{x}}$ :H layers}

Fig. 4 shows the minority charge carrier lifetime values at different grain boundary types in mc-Si samples from ingot 1 (subfigures (a) and (c)) and from ingot 2 (subfigures (b) and (d)). Subfigures (a) and (b) present results of samples from group $\mathrm{A} / \mathrm{B}$ (B: with $\mathrm{POCl}_{3}$ diffusion before hydrogenation, compare Sec. III) and subfigures (c) and (d) of samples from group C (no P gettering before hydrogenation).

Values of different grain boundary types are separated by vertical lines into segments in all graphs of Fig. 4. The box plots in one segment belong to different process histories. In subfigures (a) and (b), the gray left hand box plot shows the lifetime value statistics at grain boundaries of the according grain boundary type of the as-grown sample. The red center box plot displays lifetime values at this grain boundary type after $\mathrm{P}$ gettering of the same sample, the blue right hand box plot gives these values on a neighboring sample after $\mathrm{P}$ gettering and hydrogenation. The medians, 25 and 75 percentiles are marked by horizontal bars, the arithmetic average values by black dots. The values in brackets on top of the graph give the number of analyzed data points per sample for the corresponding grain boundary type. Figs. 2 and 3 show the PL images and grain boundaries where the values after different processes (as-grown, after $\mathrm{POCl}_{3}$, after $\mathrm{POCl}_{3}+\mathrm{SiN}_{\mathrm{x}}: \mathrm{H}$ firing) presented in Fig. 4(b) were taken from.

The lifetimes at grain boundaries after the processes in the samples from ingot 2 (Figs. 4(b) and 4(d)) are generally higher than the ones in the samples from ingot 1 (Figs. 4(a) and 4(c)). This might be explained by the lower concentration of impurities throughout the whole ingot. To verify this assumption, approximately $4 \times 30 \times 2.5 \mathrm{~mm}^{3}$ sized mc-Si pieces (approximately $0.7 \mathrm{~g}$ ) were cut out of the two ingots from positions close to the ones the examined samples were taken from and were analyzed by inductively coupled plasma mass spectrometry (ICP-MS) ${ }^{49,50}$ after cleaning the pieces by etching off the saw damage and other external contamination. The results are presented in Fig. 5. The concentrations of nearly all kind of impurities are higher in ingot 1 than in ingot 2 at the investigated position in the ingots.

Focusing on the median lifetime values of the cleaner samples from ingot 2 presented in Fig. 4(b), a clear trend of 


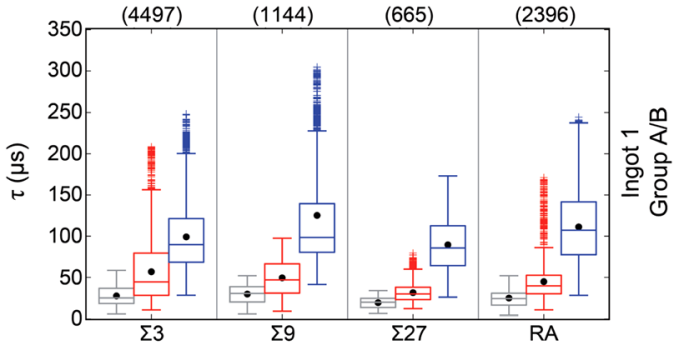

(a)

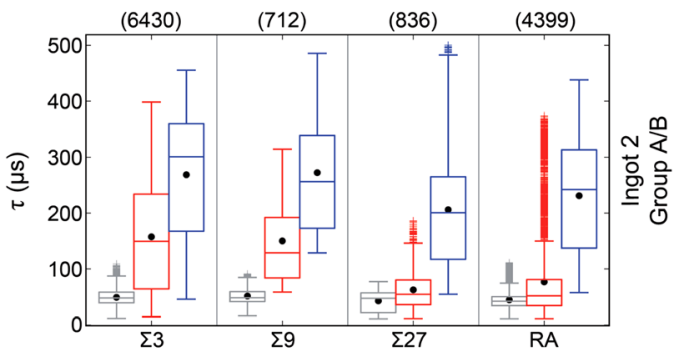

(b)

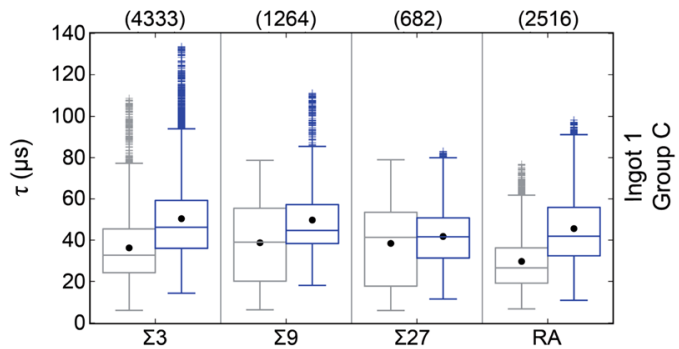

(c)

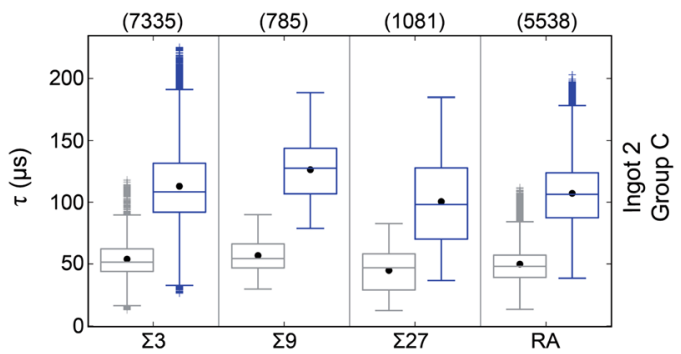

(d)

FIG. 4. Minority charge carrier lifetime values at different grain boundary types (separated by vertical lines into segments) in mc-Si samples after different processes. Box plots in each segment belonging to following process history: (a) + (b) left (gray): as-grown, center (red): after P gettering, right (blue): after P gettering and hydrogenation; (c) + (d) left (gray): as-grown, right (blue): after hydrogenation. The medians, 25 and 75 percentiles are marked by horizontal bars, the average values by black dots. The number of analyzed data points per grain boundary type is given in brackets. (a) + (c) show data of neighboring samples (group $\mathrm{A} / \mathrm{B}+\mathrm{C}$, respectively) from ingot 1 , and (b) $+(d)$ from ingot 2 .

the lifetime values after the applied processes is visible for all CSL grain boundary types. The as-grown medians are very similar for all grain boundary types; but after the processing steps, the improvements of the lifetime medians show a dependence on the grain boundary types. Comparing the median lifetime values of grain boundaries with different CSL grain boundary types after the same processing steps, it can be stated based on broad statistics that a higher CSL value leads to lower lifetimes. This is true both for lifetimes

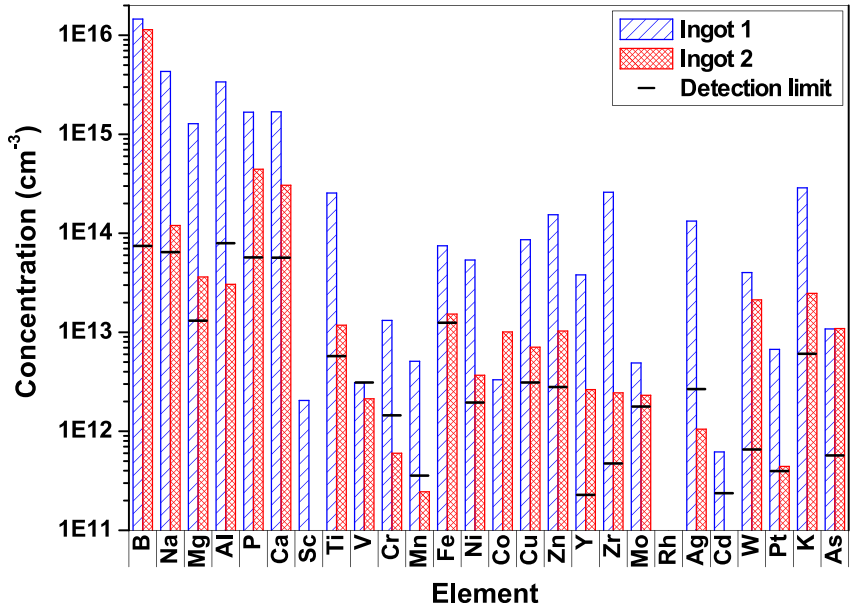

FIG. 5. ICP-MS results for samples out of ingot 1 and ingot 2 (compare Sec. III). The black horizontal bars give the detection limits. Note that values falling below the detection limit are recorded as well.

after $\mathrm{P}$ gettering and after $\mathrm{P}$ gettering and hydrogenation. This fact correlates very well with the trend of stronger decoration of grain boundaries with metal impurities with higher CSL indexes described in Ref. 51. Fig. 4(a) presents data of the only sample that does not completely follow this trend. Surprisingly, the median lifetime values at random angle grain boundaries after $\mathrm{P}$ gettering and hydrogenation are slightly higher than at $\Sigma 27$ grain boundaries for all presented samples. This observation cannot be explained yet and does not fit into the observed trends for CSL grain boundaries. From the higher decoration with impurities ${ }^{51}$ and the higher degree of misorientation, lower median lifetime values would be expected at random angle grain boundaries. A possible statistical explanation for this observation is further discussed in Sec. V.

Regarding the evolution of the median lifetimes of the grain boundaries after the different processing steps separated by grain boundary types, a continuous improvement of lifetimes after the applied processes is visible in all graphs of Fig. 4. According to literature, ${ }^{22}$ a lifetime decrease at grain boundaries was expected after $\mathrm{POCl}_{3}$ diffusion. This could not be observed in the analyzed samples for CSL grain boundaries. The median lifetime values further increased at all grain boundaries after $\mathrm{POCl}_{3}$ diffusion with subsequent firing of $\mathrm{SiN}_{\mathrm{x}}: \mathrm{H}$ layers.

The lifetime results for neighboring samples that did not receive a $\mathrm{POCl}_{3}$ diffusion but were hydrogenated by firing PECVD $\mathrm{SiN}_{\mathrm{x}}: \mathrm{H}$ layers directly are presented in Figs. 4(c) and $4(\mathrm{~d})$. In these graphs, the data are arranged analogically to Figs. 4(a) and 4(b), with the difference that the gray left hand box plots in the segments show the as-grown lifetime values at the corresponding grain boundary types and the blue right hand box plots give the lifetime statistics after hydrogenation. The PL images belonging to this statistics are not presented.

Again, the as-grown values are very similar at all grain boundary types. The lifetime values at all grain boundaries improved after hydrogenation. For all analyzed samples, the best median lifetime values after firing PECVD $\mathrm{SiN}_{\mathrm{x}}: \mathrm{H}$ layers were observed at $\Sigma 3$ grain boundaries, except for the 
sample from ingot 2 (Fig. 4(d)) where the best median results were measured at $\Sigma 9$ grain boundaries (the best overall lifetime values after direct hydrogenation are still found at $\Sigma 3$ grain boundaries for all analyzed samples). Therefore, it can be stated again that the median lifetime values at grain boundaries are inversely correlated to the height of the CSL grain boundary type indexes. Again, the results at the random angle grain boundaries do not fit completely into this trend. Compared to the values after hydrogenation of very similar neighboring $\mathrm{POCl}_{3}$ gettered samples (Figs. 4(a) and 4(b)), the lifetime values of the directly hydrogenated samples are much lower at all grain boundaries.

\section{B. Lifetime contrast values at different grain boundary types as-grown, after $\mathrm{POCl}_{3}$ diffusion and/or firing of PECVD $\operatorname{SiN}_{\mathrm{x}}: \mathrm{H}$ layers}

As shown in Sec. IV A, lifetimes at the CSL grain boundaries after the different processing steps generally increase. But Fig. 2 demonstrates that the lifetime values in the grains also increase. To evaluate if the recombination activity of a grain boundary has been passivated or is still harmful compared to the rest of the material, the lifetime at the grain boundary has to be compared to the lifetime in the bordering grains.

A measure to quantify the recombination strength of a grain boundary compared to bordering grains is given by the lifetime contrast defined in Sec. II. These lifetime contrasts were calculated (Eq. (1)) for points on the marked grain boundaries (white frames around colored lines in Fig. 3) where the conditions of Sec. II were fulfilled. The corresponding data are presented in Fig. 6. Plots of lifetime contrast data from the same samples as shown in Fig. 4 are arranged analogically to Fig. 4: Figs. 6(a) and 6(c) show data from ingot 1 and Figs. 6(b) and 6(d) from ingot 2. Subfigures (a) and (b) present results of samples from group A/B (B: with $\mathrm{POCl}_{3}$ diffusion before hydrogenation, compare Sec. III) and subfigures (c) and (d) of samples from group C (no P gettering before hydrogenation). Note that much less data points were analyzed because only few points on the grain boundaries fulfill the requested conditions for the calculation of lifetime contrasts.

The results are different when the recombination activities at grain boundaries are evaluated in terms of lifetime contrasts. The influence of a $\mathrm{POCl}_{3}$ diffusion to lifetime contrasts is shown by the red box plots in Figs. 6(a) and 6(b). The median lifetime contrast values for all CSL grain boundary types are higher after P gettering of the sample from ingot 1 compared to the values of the as-grown sample. This shows that an analysis based on the calculations of lifetime contrast values leads to further important information that is not accessible from the lifetime values shown in Fig. 4. Although the according median lifetime values increased after $\mathrm{P}$ gettering, the lifetime contrast values increase. The reason therefore is that the increase in lifetime at the grain boundaries is lower than the one in bordering grains. This was expected from literature ${ }^{7,21,22,52}$ and can be explained by a redistribution of impurities. During the high temperatures of a $\mathrm{POCl}_{3}$ diffusion above $800^{\circ} \mathrm{C}$, impurity precipitates as, for example, Fe precipitates can dissolve ${ }^{52,53}$ and

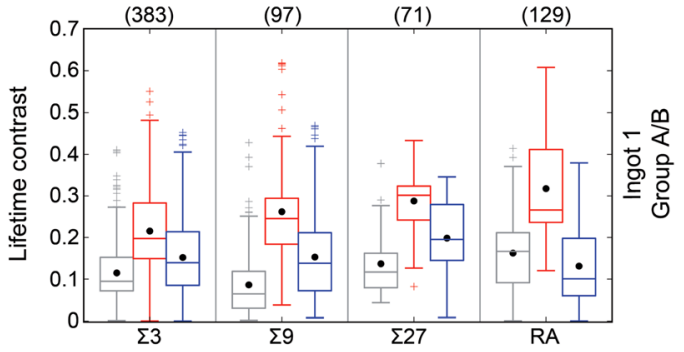

(a)

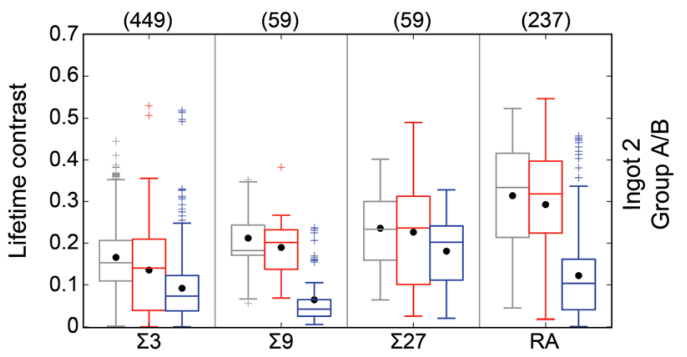

(b)

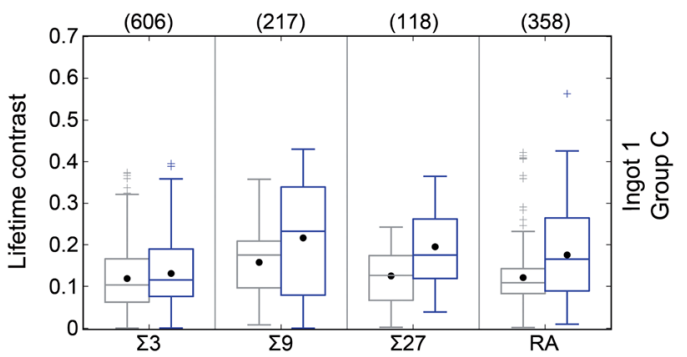

(c)

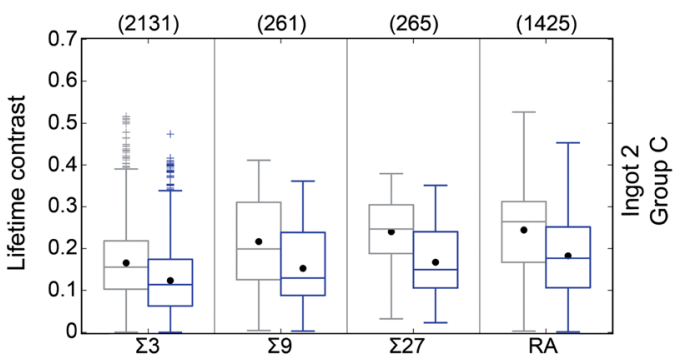

(d)

FIG. 6. Lifetime contrast values (calculated according to conditions described in Sec. II) at different grain boundary types (separated by vertical lines into segments) in neighboring mc-Si samples after different processes. Box plots in each segment belonging to following process history: (a)+(b) left (gray): as-grown, center (red): after P gettering, right (blue): after P gettering and hydrogenation; (c) + (d) left (gray): as-grown, right (blue): after hydrogenation. The medians, 25 and 75 percentiles are marked by horizontal bars, the average values by circles. The number of analyzed data points per grain boundary type is given in brackets. (a)+(c) show data of neighboring samples (group $\mathrm{A} / \mathrm{B}+\mathrm{C}$, respectively) from ingot 1 , and (b) $+(\mathrm{d})$ from ingot 2 .

the mono-atomic impurities can diffuse through the Si crystal. These impurities cannot only be gettered externally in the phosphorus silicate glass layers that subsequently are removed but also at internal getter sinks as for example grain boundaries. Two mechanisms can be responsible for internal gettering at grain boundaries: precipitation of supersaturated impurities and segregation due to higher solubility in the strain field of a grain boundary. ${ }^{52}$ At a grain boundary, the two processes of external and internal getterings happen 
simultaneously during a $\mathrm{POCl}_{3}$ diffusion. In contrast to the situation in bordering grains where the overall impurity concentration is only lowered by external gettering, at grain boundaries, the net change in impurity concentration has to be considered because impurities from the grains can be trapped at the grain boundaries. As the lifetime values at grain boundaries are higher after $\mathrm{P}$ gettering, we assume that the impurity concentration has been lowered due to the process, but not to the same extend as in bordering grains. The relation of recombination activity at grain boundaries compared to the activity in bordering grains is enhanced due to $\mathrm{P}$ gettering resulting in higher median lifetime contrast values after $\mathrm{P}$ gettering compared to the as-grown samples.

The median lifetime contrast values after $\mathrm{P}$ gettering of the cleaner sample from ingot 2 (Fig. 6(b)) behave differently: at $\Sigma 3$ and RA grain boundaries, they even decrease slightly, the increase at the other CSL grain boundary types is very small. The behavior of the two different materials in terms of lifetime contrast values is even more contrary after $\mathrm{P}$ gettering and subsequent firing of $\mathrm{SiN}_{\mathrm{x}}$ :H layers (blue right hand boxes in the different segments). The median lifetime contrast values after all processes in material from ingot 1 (blue boxes in Fig. 6(a)) do not reach the as-grown lifetime contrast values (gray boxes) for none of the CSL grain boundary types, while these values are well below the as-grown lifetime contrast values for the sample from ingot 2 (Fig. 6(b)). The values of the sample from ingot 2 are generally smaller than the ones of the sample from ingot 1 . These results can be explained by the different concentrations of impurities presented in Fig. 5. If there are too many impurity atoms or precipitates at the grain boundaries after $\mathrm{P}$ gettering, hydrogenation is less effective in reducing the recombination activity. This is in agreement with the pre-experiment where both-sided PECVD $\mathrm{SiN}_{\mathrm{x}}: \mathrm{H}$ layers on neighboring mc-Si samples were fired after $\mathrm{P}$ gettering with and without emitters present (results presented on right hand side of Fig. 2) and hydrogenation was much more effective on the samples with emitters, especially at grain boundaries. Less impurity concentration improves efficacy of hydrogenation in mc-Si.

The lifetime contrast values after hydrogenation are lower than the ones after $\mathrm{P}$ gettering for all samples and grain boundary types. This means that the effect of hydrogenation is more beneficial at grain boundaries than in grains. This observation is in accordance with formerly reported results. ${ }^{24}$

By comparing the median lifetime contrast values of one sample after the same processing steps at different grain boundary types, a dependence on the CSL grain boundary type can be stated: higher CSL grain boundary indexes seem to cause higher lifetime contrast values. This is true for all analyzed samples except for the sample from ingot 2 that shows a small deviation from this trend for lifetime contrast values after $\mathrm{P}$ gettering and hydrogenation at $\Sigma 9$ grain boundaries (Fig. 6(b)). After $\mathrm{P}$ gettering alone, this tendency is shown clearly by all samples confirming formerly reported results. ${ }^{26}$ With high probability, this observation can be explained by the higher degree of misorientation between neighboring grains with grain boundaries of higher CSL indexes. The solubility of metal impurities during $\mathrm{POCl}_{3}$ diffusion is higher at grain boundaries than in the grains because of the strain field around the grain boundary. ${ }^{52}$ It seems reasonable that the strength of the strain field is correlated with the CSL indexes and the degree of higher solubility. This could explain the higher lifetime contrast values at CSL grain boundaries with higher CSL indexes. For the same reason, the degree of decoration of CSL grain boundaries in as-grown mc-Si samples intentionally contaminated with transition metal impurities correlates with the height of the CSL indexes. ${ }^{51}$

The different reaction of the different materials to the applied processing steps is very clearly visible for the samples from group $\mathrm{C}$ that were hydrogenated directly without former P gettering. Figs. 6(c) and 6(d) show the lifetime contrasts for the samples from ingots 1 and 2, respectively. After hydrogenation, the lifetime contrasts in the cleaner sample (d) decrease, but increase in the sample from ingot 1 (c). This could be explained as well by internal gettering of the grain boundaries during the deposition of the PECVD $\mathrm{SiN}_{\mathrm{x}}: \mathrm{H}$ layers at $450{ }^{\circ} \mathrm{C}$ for approximately $2 \mathrm{~h}$. For example, interstitial iron is known to form precipitates at this temperature ${ }^{53,54}$ and grain boundaries are preferential sites where precipitates can form. ${ }^{55}$ Such a decoration of grain boundaries in mc-Si after firing of PECVD $\mathrm{SiN}_{\mathrm{x}}: \mathrm{H}$ was formerly observed based on electron beam induced current (EBIC) analyses. ${ }^{56}$ This could lead to a stronger decoration of grain boundaries in the more contaminated material from ingot 1 (compare Fig. 5). For that reason, the less contaminated grain boundaries from ingot 2 could be better passivated by $\mathrm{H}$ from the $\mathrm{SiN}_{\mathrm{x}}: \mathrm{H}$ layers.

\section{Interstitial iron concentrations at different grain boundary types as-grown, after $\mathrm{POCl}_{3}$ diffusion and firing of PECVD $\mathrm{SiN}_{\mathrm{x}}$ :H layers}

In Secs. IV A and IV B, a dependency of the minority charge carrier lifetimes at grain boundaries on the grain boundary type could be reported. Interstitial iron is an important impurity with big influence on lifetimes in mc-Si. For this reason, the interstitial iron concentration $\left[\mathrm{Fe}_{\mathrm{i}}\right]$ of all samples was measured before and after the processes as described in Sec. III, and the $\left[\mathrm{Fe}_{\mathrm{i}}\right]$ at the grain boundaries was analyzed analogical to the lifetimes as in Sec. IV A.

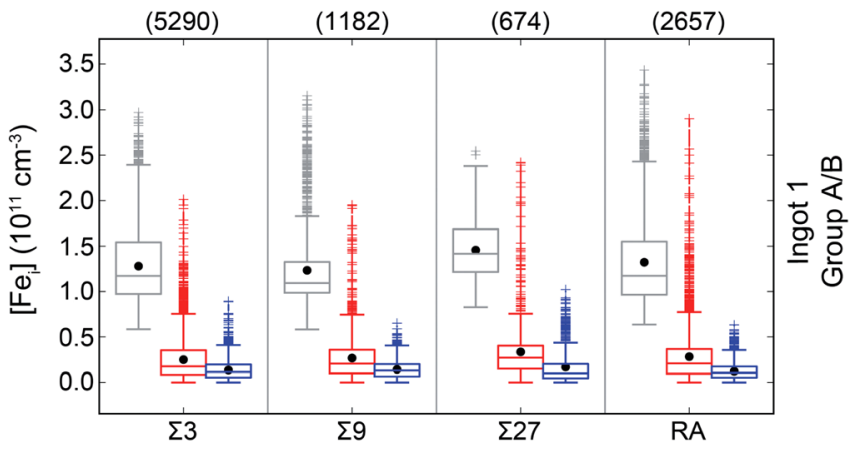

FIG. 7. Interstitial iron concentrations at different grain boundary types (separated by vertical lines into segments) in neighboring mc-Si samples from ingot 1 after different processes. Box plots in each segment belonging to following process history: left (gray): as-grown, center (red): after P gettering, right (blue): after $\mathrm{P}$ gettering and hydrogenation. The medians, 25 and 75 percentiles are marked by horizontal bars, the average values by circles. The number of analyzed data points per grain boundary type is given in brackets. Only the data from group B (compare Fig. 1) are presented. 
Fig. 7 shows the results for samples from group A and group B from ingot 1 (compare Fig. 4(a)). As all other box plots for the $\left[\mathrm{Fe}_{\mathrm{i}}\right]$ results look similar, only this one is presented. The essential information gained from Fig. 7 is that there is no dependence on the CSL grain boundary types for the $\left[\mathrm{Fe}_{\mathrm{i}}\right]$ after the processes. It is shown based on broad statistics that independently of the CSL type the $\left[\mathrm{Fe}_{\mathrm{i}}\right]$ is very similar for the different grain boundary types after $\mathrm{P}$ gettering and after $\mathrm{P}$ gettering and hydrogenation. The $\left[\mathrm{Fe}_{\mathrm{i}}\right]$ decreases after the different processing steps, but in the same manner for all CSL grain boundaries. The results of Ref. 23 could be confirmed based on broad statistics: $\left[\mathrm{Fe}_{\mathrm{i}}\right]$ is not the reason for the dependence of lifetime values at grain boundaries on the CSL grain boundary type.

\section{DISCUSSION}

Many results of this investigation indicate that hydrogenation of cleaner grains and grain boundaries is more efficient. In the following, these results are listed in detail:

- Emitters as external gettering site present during hydrogenation compared to etching off emitters prior to hydrogenation lead to higher lifetimes (Fig. 2).

- Lifetimes at grain boundaries of ingot 2 (crystallization in cleaner crucible) are higher after hydrogenation than the ones of ingot 1 (standard crystallization) (Fig. 4).

- Lifetimes at grain boundaries are higher after hydrogenation with preceding $\mathrm{P}$ gettering (impurities are driven to emitters and phosphorus silicate glass layers that are removed after the diffusion and after hydrogenation, respectively ${ }^{11,12}$ ) than without (Fig. 4(a/b) compared to Fig. 4(c/d), respectively).

- Less decoration of grain boundaries with impurities (small CSL index $)^{51}$ is correlated with higher lifetimes after hydrogenation compared to stronger decoration (high CSL index) (Fig. 4).

- Lifetime contrast values at CSL grain boundaries, which are a good evaluation tool for the passivation efficacy, in the cleaner sample (group B) from ingot 2 are below the as-grown lifetime contrasts, while the lifetime contrast values after hydrogenation in the corresponding samples from ingot 1 are above the as-grown values (Fig. 6).

- Lifetime contrasts at CSL grain boundaries decrease in cleaner samples after direct hydrogenation (group C), while lifetime contrasts of the samples from ingot 1 increase after the same process (Fig. 6).

A conclusion of these observations could be that impurities at grain boundaries in form of atoms or precipitates hinder the passivation of dangling bonds by atomic hydrogen during firing of PECVD $\mathrm{SiN}_{\mathrm{x}}: \mathrm{H}$ layers.

In the following, the statistical relevance and reliability of the results shall be discussed. As already mentioned in Sec. III, the changes of lifetimes at grain boundaries due to the different processing steps cannot be considered to be evaluated quantitatively. The effective lifetimes at grain boundaries after the different processes can be influenced by minority charge carriers diffusing towards the grain boundaries from neighboring grains, where more carriers were injected. In this case, the excess charge carrier density at the grain boundaries increases, resulting in higher effective lifetimes (compare Eq. (3)). This effect is expected to be higher for samples with longer minority charge carrier diffusion lengths within the grain. The diffusion lengths should be longer in samples after hydrogenation. For this reason, this investigation does not evaluate the change in recombination activity of the grain boundaries quantitatively (because it is influenced by the changes in the adjacent grains as well) but reflects the situations at the grain boundaries close to reality, where a solar cell is illuminated homogeneously by the sun.

Concerning the statistics, it has to be considered that the analyzed data points at one grain boundary should exhibit very similar properties and that it is more important to analyze many different grain boundaries of one CSL type than to analyze many points at one grain boundary. This could explain the small deviations from the observed trends. Nevertheless, as shown in Fig. 3, still significant amounts of spatially separated grain boundaries from all types are analyzed. The described analysis method was applied to many further samples that were not taken into this publication. All these results of further investigations show the described trends. The maximum difference (Eq. (2)) of intra-grain lifetime values at the two sides of grain boundaries was accepted to be $20 \%$, what is rather much. Note that the trend of the results in the presented graphs does not change at all, when this limit is decreased to $10 \%$. Only the number of analyzed data points is slightly smaller.

Note that the character of grain boundaries is not completely determined by its CSL index that only describes the orientation of the bordering grains and not the position and orientation of the common surface of the two grains. But it is very probable that there exist preferential surface orientations and that the CSL indexes are correlated to certain surface orientations. Nevertheless, a more detailed microscopic analysis and a further classification within the CSL grain boundary types could reduce the observed deviations in lifetimes after the processes for one CSL type.

\section{SUMMARY}

Based on broad statistics, it can be stated that the minority charge carrier lifetimes at grain boundaries in mc-Si after $\mathrm{P}$ gettering and/or firing of PECVD SiN $\mathrm{x}$ :H layers depend on the CSL grain boundary type: higher CSL indexes are correlated with lower lifetimes.

In contrast to formerly reported results, ${ }^{22}$ no lifetime decrease at grain boundaries after $\mathrm{P}$ gettering could be observed. But in standard solar-grade material (ingot 1), an increase of lifetime contrast values was detected for all grain boundary types. The increase was stronger for higher CSL indexes. After subsequent hydrogenation of this material, the lifetime contrast values still were above the as-grown levels, again the values were higher for higher CSL indexes.

Cleaner material showed a different evolution of lifetime contrast values after the different processes. The values of samples from ingot 2 decreased both after $\mathrm{P}$ gettering and after direct hydrogenation.

It was observed that hydrogenation of the whole samples (in grains and at grain boundaries) generally is more efficient 
in cleaner mc-Si material. A pre-experiment revealed that hydrogenation is more efficient if the emitters are still present during hydrogenation and can serve as external gettering sinks during deposition and firing of PECVD $\mathrm{SiN}_{\mathrm{x}}: \mathrm{H}$ layers.

In total, a good correlation between CSL grain boundary types and lifetimes at grain boundaries was found. No dependency of the $\left[\mathrm{Fe}_{\mathrm{i}}\right]$ on the CSL grain boundary type could be found, indicating that the reason for the observed dependency on the grain boundary type rather could correlate with the dependency of dislocation density with the CSL grain boundary type, as formerly reported. ${ }^{23}$

In order to improve the quality of mc-Si wafers, ingots with grain boundaries with only small CSL indexes are eligible. As according to current investigations, a correlation between large grain sizes and a higher frequency of grain boundaries with smaller CSL indexes seems to be very probable,$^{57}$ the directional solidification process has to be further developed producing ingots with larger grains. Larger grains can be achieved by controlling the nucleation at the crucible bottom. ${ }^{58}$ It already has been demonstrated that dendritic growth conditions result in large grained ingots with mostly $\Sigma 3$ grain boundaries and low dislocation densities. ${ }^{57}$

\section{ACKNOWLEDGMENTS}

The authors would like to thank B. Herzog and G. Micard for fruitful discussions.

This work was financially supported by the German Federal Ministry for the Environment, Nature Conservation and Nuclear Safety and by industry partners within the research cluster "SolarWinS" (Contract No. 0325270F). The content is the responsibility of the authors.

${ }^{1}$ A. Istratov, T. Buonassisi, R. McDonald, A. Smith, R. Schindler, J. Rand, J. Kalejs, and E. Weber, J. Appl. Phys. 94, 6552 (2003).

${ }^{2}$ D. Macdonald, A. Cuevas, A. Kinomura, Y. Nakano, and L. Geerligs, J. Appl. Phys. 97, 033523 (2005).

${ }^{3}$ C. Seager, Ann. Rev. Mater. Sci. 15, 271 (1985).

${ }^{4}$ V. Kveder, M. Kittler, and W. Schröter, Phys. Rev. B 63, 115208 (2001).

${ }^{5}$ G. Hahn and A. Schönecker, J. Phys.: Condens. Matter 16, R1615 (2004).

${ }^{6}$ P. Geiger, G. Kragler, G. Hahn, and P. Fath, Sol. Energy Mater. Sol. Cells Sol. Cells 85, 559 (2005).

${ }^{7}$ J. Tan, A. Cuevas, D. Macdonald, T. Trupke, R. Bardos, and K. Roth, Prog. Photovoltaics 16, 129 (2008).

${ }^{8}$ G. Hahn, M. Kaes, and B. Herzog, Solid State Phenom. 156-158, 343 (2010).

${ }^{9}$ D. Fenning, A. Zuschlag, M. Bertoni, B. Lai, G. Hahn, and T. Buonassisi, J. Appl. Phys. 113, 214504 (2013).

${ }^{10}$ S. Narayanan, S. Wenham, and M. Green, Appl. Phys. Lett. 48, 873 (1986).

${ }^{11}$ W. Schröter and R. Kühnapfel, Appl. Phys. Lett. 56, 2207 (1990).

${ }^{12}$ S. Myers, M. Seibt, and W. Schröter, J. Appl. Phys. 88, 3795 (2000).

${ }^{13}$ I. Périchaud, Sol. Energy Mater. Sol. Cells 72, 315 (2002).

${ }^{14}$ M. Seibt, A. Sattler, C. Rudolf, O. Voß, V. Kveder, and W. Schröter, Phys. Status Solidi A 203, 696 (2006).

${ }^{15}$ J. Hanoka, C. Seager, D. Sharp, and J. Panitz, Appl. Phys. Lett. 42, 618 (1983).

${ }^{16} \mathrm{~J}$. Pearton, W. Corbett, and M. Stavola, Hydrogen in Crystalline Semiconductors (Springer-Verlag, 1992), p. 363.

${ }^{17}$ S. Martinuzzi, I. Périchaud, and F. Warchol, Sol. Energy Mater. Sol. Cells 80, 343 (2003).

${ }^{18} \mathrm{C}$. Dubé and J. Hanoka, in Proceedings of the 31st IEEE Photovoltaic Specialists Conference, Lake Buena Vista, 3-7 January 2005 (IEEE, New York, 2005), pp. 883-888.
${ }^{19}$ P. Karzel, A. Frey, S. Fritz, and G. Hahn, J. Appl. Phys. 113, 114903 (2013).

${ }^{20}$ T. Buonassisi, A. Istratov, S. Peters, C. Ballif, J. Isenberg, S. Riepe, W. Warta, R. Schindler, G. Willeke, Z. Cai, B. Lai, and E. Weber, Appl. Phys. Lett. 87, 121918 (2005).

${ }^{21}$ A. Liu, Y. Fan, and D. Macdonald, Prog. Photovoltaics 19, 649 (2011).

${ }^{22}$ L. Geerligs, Y. Komatsu, I. Röver, K. Wambach, I. Yamaga, and T. Saitoh, J. Appl. Phys. 102, 093702 (2007).

${ }^{23}$ M. Bertoni, S. Hudelson, B. Newman, D. Fenning, H. Dekkers, E. Cornagliotti, A. Zuschlag, G. Micard, G. Hahn, G. Coletti, B. Lai, and T. Buonassisi, Prog. Photovoltaics 19, 187 (2011).

${ }^{24} \mathrm{M}$. Rinio, A. Hauser, and H. Möller, in Proceedings of the $3 \mathrm{rd}$ World Conference on Photovoltaic Energy Conversion, Osaka, 11-18 May 2003 (IEEE, New York, 2003), pp. 112-115.

${ }^{25} \mathrm{G}$. Gottstein, Physikalische Grundlagen der Materialkunde, 3rd ed. (Springer, Berlin, 2007).

${ }^{26}$ I. Takahashi, N. Usami, H. Mizuseki, Y. Kawazoe, G. Stokkan, and K. Nakajima, J. Appl. Phys. 109, 033504 (2011).

${ }^{27}$ A. Fedotov, A. Mazanik, and A. Ulyashin, Sol. Energy Mater. Sol. Cells 72, 589 (2002).

${ }^{28}$ J. Chen, T. Sekiguchi, D. Yang, F. Yin, K. Kido, and S. Tsurekawa, J. Appl. Phys. 96, 5490 (2004).

${ }^{29}$ J. Chen, D. Yang, Z. Xi, and T. Sekiguchi, Phys. B: Condens. Matter 364, 162 (2005).

${ }^{30}$ M. Rinio, M. Kaes, G. Hahn, and D. Borchert, in Proceedings of the 21 st European Photovoltaic Solar Energy Conference, Dresden, 4-8 September 2006 (WIP Renewable Energies, Munich, 2006), pp. 684-687.

${ }^{31}$ J. Junge, A. Herguth, S. Seren, and G. Hahn, in Proceedings of the 24th European Photovoltaic Solar Energy Conference, Hamburg, 21-25 September 2009 (WIP Renewable Energies, Munich, 2009), pp. 1131-1136.

${ }^{32} \mathrm{H}$. Sio, T. Trupke, S. Phang, and D. Macdonald, in Proceedings of the 27th European Photovoltaic Solar Energy Conference, Frankfurt, 24-29 September 2012 (WIP Renewable Energies, Munich, 2012), pp. 714-718.

${ }^{33}$ F. Humphreys, J. Mater. Sci. 36, 3833 (2001).

${ }^{34}$ C. Reimann, E. Meissner, M. Trempa, T. Lehmann, T. Geiger, M. Knetzger, M. Zschorsch, and J. Friedrich, in Proceedings of the 5th International Workshop on Crystalline Silicon Solar Cells, Boston, 1-3 November 2011 (2011).

${ }^{35}$ T. Trupke, R. Bardos, M. Schubert, and W. Warta, Appl. Phys. Lett. 89, 044107 (2006).

${ }^{36}$ S. Herlufsen, J. Schmidt, D. Hinken, K. Bothe, and R. Brendel, Phys. Status Solidi RRL 2, 245 (2008).

${ }^{37}$ D. Macdonald, J. Tan, and T. Trupke, J. Appl. Phys. 103, 073710 (2008).

${ }^{38}$ D. Macdonald, L. Geerligs, and A. Azzizi, J. Appl. Phys. 95, 1021 (2004).

${ }^{39}$ D. Macdonald, T. Roth, P. Deenapanray, T. Trupke, and R. Bardos, Appl. Phys. Lett. 89, 142107 (2006).

${ }^{40}$ W. Kwapil, A. Zuschlag, I. Reis, I. Schwirtlich, S. Meyer, R. Zierer, R. Krain, F. Kiessling, M. Schumann, C. Schmid, and S. Riepe, in Proceedings of the 27th European Photovoltaic Solar Energy Conference, Frankfurt, 24-29 September 2012 (WIP Renewable Energies, Munich, 2012), pp. 627-635.

${ }^{41}$ M. Meuris, P. Mertens, A. Opdebeeck, H. Schmidt, M. Depas, G. Vereecke, M. Heyns, and A. Philipossian, Solid State Technol. 38, 109 (1995).

${ }^{42}$ H. Takato, I. Sakata, and R. Shimokawa, Jpn. J. Appl. Phys., Part 2 41, L870 (2002).

${ }^{43}$ B. Chhabra, S. Bowden, R. Opila, and C. Honsberg, Appl. Phys. Lett. 96, 063502 (2010).

${ }^{44}$ K. Pollock, J. Junge, and G. Hahn, IEEE J. Photovolt. 2, 1 (2012).

${ }^{45}$ R. Sinton and A. Cuevas, Appl. Phys. Lett. 69, 2510 (1996).

${ }^{46}$ D. Kiliani, G. Micard, B. Steuer, B. Raabe, A. Herguth, and G. Hahn, J. Appl. Phys. 110, 054508 (2011).

${ }^{47}$ M. Solčanský, M. Macháček, J. Boušek, and A. Poruba, in Proceedings of the 24th European Photovoltaic Solar Energy Conference, Hamburg, 21-25 September 2009 (WIP Renewable Energies, Munich, 2009), pp. $1669-1672$.

${ }^{48}$ D. Gilles, W. Schröter, and W. Bergholz, Phys. Rev. B 41, 5770 (1990).

${ }^{49}$ R. Houk, V. Fassel, D. Flesch, A. Gray, and E. Taylor, Anal. Chem. 52(14), 2283 (1980)

${ }^{50}$ S. Nelms, Inductively Coupled Plasma Mass Spectrometry Handbook, 4th ed. (Blackwell Publishing, Oxford, 2005).

${ }^{51}$ T. Buonassisi, A. Istratov, M. Pickett, M. Marcus, T. Ciszek, and E. Weber, Appl. Phys. Lett. 89, 042102 (2006). 
${ }^{52}$ J. Schön, H. Habenicht, M. Schubert, and W. Warta, J. Appl. Phys. 109, 063717 (2011).

${ }^{53}$ A. Haarahiltunen, H. Väinölä, O. Anttila, M. Yli-Koski, and J. Sinkkonen, J. Appl. Phys. 101, 043507 (2007).

${ }^{54}$ R. Krain, S. Herlufsen, and J. Schmidt, Appl. Phys. Lett. 93, 152108 (2008).

${ }^{55}$ T. Buonassisi, A. Istratov, M. Pickett, M. Heuer, J. Kalejs, G. Hahn, M. Marcus, B. Lai, Z. Cai, S. Heald, T. Ciszek, R. Clark, D. Cunningham, A. Gabor, R. Jonczyk, S. Narayanan, E. Sauar, and E. Weber, Prog. Photovoltaics 14, 513 (2006).
${ }^{56}$ A. Zuschlag, H. Morhenn, J. Bernhard, J. Junge, S. Seren, and G. Hahn, in Proceedings of the 25th European Photovoltaic Solar Energy Conference, Valencia, 6-10 September 2010 (WIP Renewable Energies, Munich, 2010), pp. 2433-2437.

${ }^{57}$ F. Kiessling, F. Büllesfeld, N. Dropka, C. Frank-Rotsch, A. Müller, and C. Rudolph, J. Cryst. Growth 360, 81 (2012).

${ }^{58}$ K. Nakajima, N. Usami, K. Fujiwara, and K. Kutsukake, in Proceedings of the 24th European Photovoltaic Solar Energy Conference, Hamburg, 21-25 September 2009 (WIP Renewable Energies, Munich, 2009), pp. $1219-1221$. 